\title{
Preoperative narcotic utilization: accuracy of patient self-reporting and its association with postoperative narcotic consumption
}

\author{
Junyoung Ahn, BS, ${ }^{1}$ Daniel D. Bohl, MD, MPH, ${ }^{2}$ Ehsan Tabaraee, MD, ${ }^{1}$ Khaled Aboushaala, MD, ${ }^{1}$ \\ Islam M. Elboghdady, MD, ${ }^{1}$ and Kern Singh, MD'
}

'Department of Orthopedic Surgery, Rush University Medical Center, Chicago, Illinois; and 2Department of Orthopaedics and Rehabilitation, Yale School of Medicine, New Haven, Connecticut

OBJECTIVE Little is known about the accuracy of reporting of preoperative narcotic utilization in spinal surgery. As such, the purpose of this study is to compare postoperative narcotic consumption between preoperative narcotic utilizers who do and do not accurately self-report preoperative utilization.

METHODS Patients who underwent anterior cervical discectomy and fusion, minimally invasive lumbar discectomy, or minimally invasive transforaminal lumbar interbody fusion procedures between 2013 and 2014 were prospectively identified. The accuracy of self-reporting preoperative narcotic consumption was determined utilizing the Illinois Prescription Monitoring Program. Total inpatient narcotic consumption during postoperative Days 0 and 1 was compared according to the demographics and preoperative narcotic reporting accuracy. Similarly, the proportion of patients who continued to be dependent on narcotic medications at each postoperative visit was compared according to the demographics and preoperative narcotic reporting accuracy.

RESULTS A total of 195 patients met the inclusion criteria. Of these, $25 \%$ did not use narcotics preoperatively, while $47 \%$ and $28 \%$ did do so with accurate and inaccurate reporting, respectively. Patients who used narcotics preoperatively were more likely to demonstrate elevated inpatient narcotic consumption (adjusted RR 5.3; 95\% Cl 1.4-20.1; $p=0.013$ ). However, such patients were no more or less likely to be dependent on narcotic medications at the first $(p=0.618)$ or second ( $p=0.798$ ) postoperative visit. Among patients who used narcotics preoperatively, no differences were demonstrated in terms of inpatient narcotic consumption $(p=0.182)$ or narcotic dependence following the first $(p=0.982)$ or second $(p=0.866)$ postoperative visit according to the self-reported accuracy of preoperative narcotic utilization. The only preoperative factors that were independently associated with elevated inpatient narcotic consumption were workers' compensation status and procedure type. The only preoperative factors that were independently associated with narcotic dependence at the first postoperative visit were female sex, workers' compensation status, and procedure type. The only preoperative factor that was independently associated with narcotic dependence at the second postoperative visit was procedure type.

CONCLUSIONS The findings suggest that determining the actual preoperative narcotic utilization in patients who undergo spine surgery may help optimize postoperative pain management. Approximately $75 \%$ of patients used narcotics preoperatively. Patients who used narcotics preoperatively demonstrated significantly higher inpatient narcotic consumption, but this difference did not persist following discharge. Finally, postoperative narcotic consumption (inpatient and following discharge) was independent of the self-reported accuracy of preoperative narcotic utilization. Taken together, these findings suggest that corroboration between the patient's self-reported preoperative narcotic utilization and other sources of information (e.g., family members and narcotic registries) may be clinically valuable with respect to minimizing narcotic requirements, thereby potentially improving the management of postoperative pain.

http://thejns.org/doi/abs/10.3171/2015.3.SPINE141300

KEY WORDS reporting; Illinois; prescription monitoring; spine surgery; accuracy; narcotic utilization

ABBREVIATIONS ACDF = anterior cervical discectomy and fusion; BMI = body mass index; CCI = Charlson Comorbidity Index; ILPMP = Illinois Prescription Monitoring Program; OME = oral morphine equivalent; TLIF = transforaminal lumbar interbody fusion; VAS = visual analog scale.

SUBMITTED December 22, 2014. ACCEPTED March 26, 2015.

INCLUDE WHEN CITING Published online September 11, 2015; DOI: 10.3171/2015.3.SPINE141300. 
$\mathrm{T}$ HE utilization of narcotics for musculoskeletal pain in the United States has increased over the last several decades. From 1980 to 2000, the percentage of patients prescribed narcotics for acute and chronic musculoskeletal pain increased by $3 \%$ and $8 \%$, respectively. ${ }^{3} \mathrm{An}$ analysis of 26,014 patients suffering from low-back pain demonstrated that $15,830(61 \%)$ patients were prescribed at least 1 narcotic medication during the year of the study period. ${ }^{7}$

Complications associated with narcotic utilization in pain management include altered mental status (delirium), respiratory depression, pruritus, urinary retention, and gastrointestinal dysfunction (nausea, vomiting, ileus). ${ }^{14}$ Additionally, narcotic utilization has been demonstrated to be a potential risk factor for poor clinical and psychosocial outcomes following spine surgery.,11 Achieving optimal pain control and clinical outcomes, while minimizing opioid-related adverse drug events, remains a constant challenge for clinicians.

It is helpful for the treatment team to understand if a patient is preoperatively utilizing narcotics in order to optimize postoperative pain management and minimize the side effects of narcotic analgesia. The most intuitive way for a treatment team to determine if a patient is taking preoperative narcotics is to ask the patient. However, little is known about the accuracy of self-reported narcotic utilization. The purpose of this study is to determine what proportion of patients accurately self-report preoperative narcotic utilization and, among patients who use narcotics preoperatively, to compare postoperative narcotic consumption between patients who do and do not accurately report preoperative utilization.

\section{Methods \\ Patient Population}

Institutional review board approval was obtained. All patients who underwent primary anterior cervical discectomy and fusion (ACDF) procedures, minimally invasive lumbar discectomy procedures, or minimally invasive transforaminal lumbar interbody fusion (TLIF) procedures between 2013 and 2014 by a single surgeon (K.S.) were eligible for the study. Because patients were scheduled for surgery, they were included in the study registry and followed prospectively. The registry was maintained by research assistants and included all prospectively collected preoperative, intraoperative, and postoperative data. All patients were asked during their preoperative appointments if they had specifically consumed any narcotics or pain medications during the previous year. Concurrently, the 12 prior months of data in the Illinois Prescription Monitoring Program (ILPMP) were searched to determine if patients had filled prescriptions during that time. Based upon their self-report and ILPMP record, the patients were categorized into 1 of 3 groups: if the patient's self-report was negative and the registry record was negative, the patient was categorized as a nonutilizer; if the patient's self-report was positive, the patient was categorized as a utilizer with accurate reporting; or, if the patient's self-report was negative but the registry record was positive, the patient was categorized as a utilizer with inaccurate reporting.

\section{Data Collection}

After scheduling the patients for surgery, data were prospectively collected regarding demographics, comorbidity burden, body mass index (BMI), preoperative visual analog scale (VAS) pain scores, payer status, and type of procedure (ACDF vs minimally invasive lumbar discectomy vs minimally invasive TLIF). Patient comorbidity was assessed utilizing a modified Charlson Comorbidity Index (CCI). ${ }^{5}$ These modifications included 1) omitting the history of myocardial infarction, 2) adjusting liver disease to have a weight of 2 points for mild disease and 3 points for moderate to severe liver disease, and 3) omitting the age component so that age could be analyzed independently in the multivariate regression. Previous studies have demonstrated that slight modifications to CCI have minimal impact on the overall performance of the scoring system. ${ }^{5,6}$

Any intraoperative complications (e.g., iatrogenic nerve root injury, battered nerve root, or dural violation) were recorded.

Following discharge, narcotic consumption during the inpatient stay was recorded. The consumption of each narcotic was converted to oral morphine equivalents (OMEs) utilizing the conversion ratios by Gordon et al. ${ }^{8}$ The sum of the OME values on postoperative Days 0 and 1 was used as a primary outcome.

Patients typically had their first and second postoperative visits at 4 to 6 weeks and 8 to 12 weeks following surgery, respectively. For all patients, the electronic health records were queried to record any prescriptions for narcotic medications provided at the first or second postoperative visit. In addition, ILPMP was searched at least 3 months following the first and second postoperative visits to determine if the patients had filled any prescriptions for narcotic medications following each visit. Patients were considered dependent on narcotic medication if they either had been prescribed or had filled any prescriptions for narcotic medications at or following the first or second postoperative visit.

\section{Analysis}

The distribution of total postoperative narcotic consumption was examined and found to be nonnormal. For the purposes of this analysis, the 75th percentile of narcotic consumption was determined, and patients who consumed greater than the 75th percentile were categorized as having elevated postoperative narcotic consumption.

Statistical comparisons were made utilizing Poisson regression with robust error variance. All comparisons were first made without adjustment (bivariate analyses), and then with adjustment (multivariate analyses) for the following preoperative characteristics: age, sex, race, workers' compensation status, BMI, modified CCI, VAS, and procedure type. A p value $<0.05$ was considered statistically significant.

First, among all patients, all preoperative characteristics were tested for associations with preoperative narcotic utilization. Second, among only patients with preoperative narcotic utilization, all preoperative characteristics were tested for associations with inaccurate reporting. Third, among all patients, all preoperative characteristics were tested for associations with elevated inpatient narcotic 
consumption and continued narcotic dependence at the first and the second postoperative visits. Fourth, among all patients, preoperative narcotic utilization was tested for associations with inpatient narcotic consumption and continued narcotic dependence at the first and second postoperative visits. Fifth, among only patients with preoperative narcotic utilization, the accuracy of reporting was tested for associations with inpatient narcotic consumption and continued narcotic dependence at the first and second postoperative visits. Finally, elevated inpatient narcotic consumption was tested for associations with continued narcotic dependence at the first and second postoperative visits.

\section{Results}

\section{Patient Population}

A total of 195 patients met the inclusion criteria. Fortythree (22\%) of these patients underwent ACDF, 78 (40\%) underwent lumbar discectomy, and 74 (38\%) underwent TLIF. The demographics of the study population are provided in Table 1 . There were no intraoperative complications among the patient population.

\section{Preoperative Narcotic Utilization}

Among all patients, 49 (25\%) did not use narcotics preoperatively, while 91 (47\%) and 55 (28\%) did do so with accurate and inaccurate reporting, respectively (Table 2 ). The only preoperative factor that was associated with preoperative narcotic utilization was workers' compensation status: $69 \%$ of patients without workers' compensation status used narcotics preoperatively, while $87 \%$ of patients with workers' compensation status used narcotics preoperatively (adjusted RR 1.3; 95\% CI 1.1-1.6; $\mathrm{p}<$ 0.001 ; Table 3 ). Among only patients who used narcotics preoperatively (148 patients), there were no preoperative factors associated with accurate versus inaccurate reporting (unadjusted and adjusted $\mathrm{p}>0.05$; results not shown).

\section{Inpatient Narcotic Consumption}

The 75th percentile of inpatient narcotic consumption was $132.5 \mathrm{mg}$ OMEs (Fig. 1). The only preoperative factors that were independently associated with elevated inpatient narcotic consumption were workers' compensation status and procedure type: $17 \%$ of patients without workers' compensation status had elevated inpatient narcotic consumption, while $42 \%$ of patients with workers' compensation status had elevated inpatient narcotic consumption (adjusted RR 1.8; 95\% CI 1.1-3.1; $\mathrm{p}=0.031$; Table 4 and Fig. 2A); $21 \%$ of patients undergoing ACDF, $5 \%$ of patients undergoing lumbar discectomy, and $50 \%$ of patients undergoing TLIF had elevated inpatient narcotic consumption (adjusted $\mathrm{p}<0.001$; Table 4 and Fig. 3A). Patients who used narcotics preoperatively were more likely to have elevated inpatient narcotic consumption (adjusted RR 5.3; 95\% CI 1.4-20.1; $p=0.013$; Fig. 4A). Among only patients who used narcotics preoperatively, there was no difference in inpatient narcotic consumption according to the accuracy of reporting (adjusted $p=0.182$; Fig. 5A).
TABLE 1. Baseline characteristics

\begin{tabular}{|c|c|c|}
\hline Characteristic & No. of Patients & Percentage \\
\hline Total & 195 & 100 \\
\hline \multicolumn{3}{|l|}{ Age (yrs) } \\
\hline $18-39$ & 43 & 22 \\
\hline $40-49$ & 56 & 29 \\
\hline $50-59$ & 55 & 28 \\
\hline$\geq 60$ & 41 & 21 \\
\hline \multicolumn{3}{|l|}{ Sex } \\
\hline Female & 81 & 42 \\
\hline Male & 114 & 58 \\
\hline \multicolumn{3}{|l|}{ Race } \\
\hline Other & 54 & 28 \\
\hline Caucasian & 141 & 72 \\
\hline \multicolumn{3}{|c|}{ Workers' compensation } \\
\hline No & 128 & 66 \\
\hline Yes & 67 & 34 \\
\hline \multicolumn{3}{|l|}{ BMI } \\
\hline$\leq 24$ & 37 & 19 \\
\hline $25-29$ & 70 & 36 \\
\hline $30-34$ & 39 & 20 \\
\hline$\geq 35$ & 49 & 25 \\
\hline \multicolumn{3}{|l|}{ Modified CCl } \\
\hline 0 & 86 & 44 \\
\hline 1 & 43 & 22 \\
\hline 2 & 66 & 34 \\
\hline \multicolumn{3}{|l|}{ VAS score } \\
\hline $1-7$ & 102 & 52 \\
\hline $8-10$ & 93 & 48 \\
\hline \multicolumn{3}{|l|}{ Procedure } \\
\hline ACDF & 43 & 22 \\
\hline LD & 78 & 40 \\
\hline TLIF & 74 & 38 \\
\hline
\end{tabular}

$L D=$ lumbar discectomy.

\section{Continued Narcotic Dependence at the First Postoperative Visit}

In total, $29 \%$ of patients continued to be dependent on narcotic medications at the first postoperative visit. The only preoperative factors that were independently associated with dependence were sex, workers' compensation status, and procedure type: $28 \%$ of males and $30 \%$ of females continued to be dependent on narcotic medications

TABLE 2. Self-reporting versus registry recording of narcotic use

\begin{tabular}{clcc}
\hline & \multicolumn{2}{c}{ Registry Record of Use } & \\
\cline { 2 - 3 } Self-Report & No $(\%)$ & Yes (\%) & Total (\%) \\
\hline No & $49(25)^{*}$ & $55(28) \dagger$ & $104(53)$ \\
\hline Yes & $37(19)$ & $54(28)$ & $91(47) \ddagger$ \\
\hline Total & $86(44)$ & $109(56)$ & $195(100)$ \\
\hline
\end{tabular}

* These patients were categorized as nonusers.

$\dagger$ These patients were categorized as users with inaccurate reporting.

$\ddagger$ These patients were categorized as users with accurate reporting. 
TABLE 3. Bivariate and multivariate associations with preoperative narcotic use*

\begin{tabular}{|c|c|c|c|c|c|}
\hline \multirow[b]{2}{*}{ Characteristic } & \multicolumn{2}{|c|}{ Bivariate Analysis } & \multicolumn{3}{|c|}{ Multivariate Analysis } \\
\hline & Percentage & p Value & $\mathrm{RR}$ & $95 \% \mathrm{Cl}$ & $p$ Value \\
\hline Age (yrs) & & 0.339 & & & 0.057 \\
\hline $18-39$ & 70 & & Ref & & \\
\hline $40-49$ & 82 & & 1.3 & $1.0-1.6$ & \\
\hline $50-59$ & 69 & & 1.0 & $0.7-1.3$ & \\
\hline$\geq 60$ & 78 & & 1.2 & $0.8-1.6$ & \\
\hline Sex & & 0.906 & & & 0.283 \\
\hline Female & 75 & & Ref & - & \\
\hline Male & 75 & & 0.9 & $0.8-1.1$ & \\
\hline Race & & 0.188 & & & 0.529 \\
\hline Other & 81 & & Ref & - & \\
\hline Caucasian & 72 & & 0.9 & $0.8-1.1$ & \\
\hline Workers' compensation & & 0.003 & & & $<0.001$ \\
\hline No & 69 & & Ref & & \\
\hline Yes & 87 & & 1.3 & $1.1-1.6$ & \\
\hline BMI & & 0.578 & & & 0.300 \\
\hline$\leq 24$ & 76 & & Ref & & \\
\hline $25-29$ & 70 & & 1.0 & $0.8-1.2$ & \\
\hline $30-34$ & 82 & & 1.2 & $0.9-1.5$ & \\
\hline$\geq 35$ & 76 & & 1.0 & $0.8-1.2$ & \\
\hline Modified CCl & & 0.425 & & & 0.228 \\
\hline 0 & 78 & & Ref & & \\
\hline 1 & 67 & & 0.9 & $0.7-1.1$ & \\
\hline 2 & 76 & & 1.1 & $0.8-1.4$ & \\
\hline VAS score & & 0.903 & & & 0.757 \\
\hline $1-7$ & 75 & & Ref & & \\
\hline $8-10$ & 75 & & 1.0 & $0.9-1.2$ & \\
\hline Procedure & & 0.163 & & & 0.164 \\
\hline ACDF & 70 & & Ref & & \\
\hline LD & 71 & & 1.1 & $0.9-1.4$ & \\
\hline TLIF & 82 & & 1.2 & $1.0-1.5$ & \\
\hline
\end{tabular}

Ref $=$ reference

* Values in boldface are statistically significant.

(adjusted RR 0.6; 95\% CI 0.4-1.0; p = 0.032; Table 4); $48 \%$ of patients with workers' compensation status were dependent, while $19 \%$ of patients without workers' compensation status were dependent (adjusted RR 2.1; 95\% CI 1.3-3.5; $\mathrm{p}=0.004$; Table 4 and Fig. 2B); $26 \%$ of patients undergoing ACDF, $9 \%$ of patients undergoing lumbar discectomy, and $50 \%$ of patients undergoing TLIF continued to be dependent (adjusted $p=0.001$; Table 4 and Fig. 3B). There was no difference in narcotics dependence according to preoperative narcotic utilization (adjusted $\mathrm{p}$ $=0.618 ;$ Fig. 4B). Among only patients who used narcotics preoperatively, there was no difference in narcotic dependence according to the accuracy of reporting (adjusted $\mathrm{p}$ $=0.982$; Fig. 5B). Patients whose inpatient narcotic consumption was elevated were more likely to demonstrate narcotic dependence (unadjusted RR 2.5; 95\% CI 1.7-3.8; $\mathrm{p}<0.001$ ); however, this difference did not persist following adjustment (adjusted $\mathrm{p}=0.446$; Fig. 6A).

\section{Continued Narcotic Dependence at the Second Postoperative Visit}

In total, $18 \%$ of patients continued to be dependent on narcotic medications following the second postoperative visit. The only preoperative factor that was independently associated with dependence was the procedure type: $14 \%$ of patients undergoing ACDF, $6 \%$ of patients undergoing lumbar discectomy, and $34 \%$ of patients undergoing TLIF remained dependent (adjusted $\mathrm{p}=0.028$; Table 4 and Fig. $3 \mathrm{C})$. Of note, workers' compensation payment status was not associated with dependence $(\mathrm{p}=0.224$; Table 4 and Fig. 2C) There was no difference in narcotics dependence according to preoperative narcotic utilization (adjusted $\mathrm{p}$ $=0.798 ;$ Fig. 4C). Among only patients who used narcotics preoperatively, there was no difference in the proportion of patients who continued to be dependent according to the accuracy of reporting (adjusted $p=0.866$; Fig. 5C). Patients who demonstrated elevated inpatient narcotic 


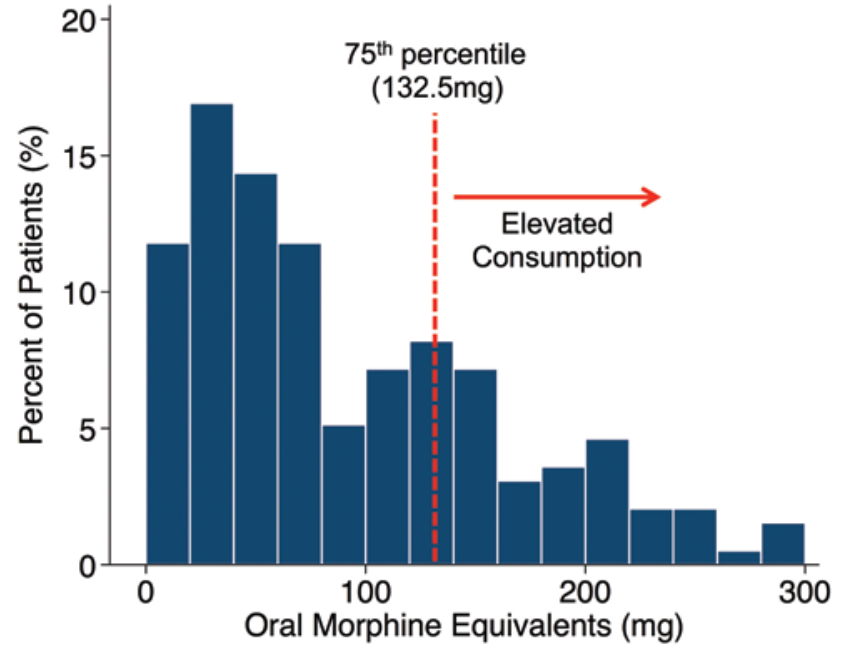

FIG. 1. Distribution of inpatient narcotic consumption. The vertical dotted line indicates the 75th percentile for narcotics consumption, which was $132.5 \mathrm{mg}$ OMEs. Patients were considered to have elevated inpatient narcotic consumption if their narcotic consumption exceeded $132.5 \mathrm{mg}$. Figure is available in color online only.

consumption were more likely to demonstrate narcotic dependence (unadjusted RR 3.2; 95\% CI 1.8-5.7; p < 0.001); however, this difference did not persist following adjustment (adjusted $\mathrm{p}=0.170$; Fig. 6B).

\section{Discussion}

The literature documents a close association between the chronic utilization of narcotics, inadequate pain management, and suboptimal surgical outcomes.,9,12,15 Accordingly, the accurate identification of patients who use narcotic medications prior to spine surgery may help ensure proper recovery and expedite narcotic independence.

In our analysis, patients who used preoperative narcotics had significantly higher inpatient narcotic requirements than opioid-naive patients. This finding is consistent with previous studies characterizing increased narcotic requirements in patients who used preoperative narcotics., ${ }^{2,412}$ Rapp et al. compared the amount of opioids consumed via patient-controlled analgesia in the immediate postoperative period following urological, gynecological, orthopedic, and general surgical procedures. ${ }^{12}$ The authors demonstrated that the mean morphine consumption was significantly higher in patients who used narcotics preoperatively than in those who did not (135.8 vs $42.8 \mathrm{mg}$, respectively). ${ }^{12}$ Similarly, Chapman et al. demonstrated that patients who used narcotics prior to elective surgery experienced postoperative pain for a significantly longer period of time than patients who did not consume preoperative narcotics. ${ }^{4}$

Interestingly, the association between preoperative narcotic utilization and elevated inpatient narcotic consumption did not persist following the first postoperative visit. Specifically, patients who used narcotics preoperatively were no more or less likely to be dependent on narcotic medications following the first or second postoperative visit. Similarly, elevated inpatient narcotic consumption was not an independent risk factor for continued narcotic dependence at the first or second postoperative visit.
Of the 195 spine surgery patients included in the present study, $75 \%$ used narcotics preoperatively and $28 \%$ inaccurately reported preoperative narcotics utilization at the initial preoperative visit. We had hypothesized that the inaccurate self-reporting of narcotic utilization may be a risk factor for higher postoperative narcotic consumption. However, inaccurate reporting was not a risk factor for increased inpatient or postoperative narcotic consumption. As noted, postoperative narcotic consumption was significantly higher in patients who used narcotics prior to surgery than in patients who did not. As such, a nonjudgmental and understanding approach by the surgeon and treatment team to verify the actual preoperative utilization of narcotics may help improve postoperative pain management and surgical outcomes.

Interestingly, procedure type was closely associated with postoperative narcotic consumption in both the inpatient and postdischarge settings. The TLIF patients were the most likely to demonstrate elevated postoperative narcotics consumption, while the lumbar discectomy patients were least likely. It is not surprising that the patients who underwent TLIF procedures consumed greater amounts of postoperative narcotics, as lumbar fusion procedures involve greater periosteal and osseous disruption than ACDF or lumbar discectomy procedures. Similarly, lumbar discectomy procedures involve the least amount of periosteal and osseous disruption of these 3 procedures, which may account for the findings.

In our analysis, workers' compensation payer status was identified as an independent risk factor for preoperative narcotic utilization, as well as increased postoperative narcotic consumption in both inpatient and postdischarge settings. Previous studies have highlighted the impacts of increased narcotic utilization on the populations receiving workers' compensation. ${ }^{10,13}$

Webster et al. analyzed the association between early narcotic utilization and clinical outcomes in 8443 patients with low-back pain receiving workers' compensation. ${ }^{13}$ The authors found that patients who received higher dosages of narcotics (> $140 \mathrm{mg}$ OMEs) were at significantly increased risk for prolonged disability, prolonged narcotics utilization, and higher medical costs. Similarly, Mahmud et al. demonstrated that patients who used narcotics for more than 7 days were at increased risk of prolonged disability. ${ }^{10}$ The present study's findings may be attributed to differences in the mechanism of injury between patients receiving and those not receiving workers' compensation. It is plausible that patients receiving workers' compensation incurred more severe occupational-related injuries compared with the degenerative pathologies more often observed in the rest of the population. Regardless, physicians should be cognizant of the fact that workers' compensation patients, especially those who use narcotics preoperatively, may be at increased risk of slower weaning off of narcotic medications following surgery between the immediate postoperative period and the second postoperative visit.

This study has several limitations. First, preoperative narcotic utilization was not quantified: the amount of narcotics as well as the extent of opioid tolerance may have substantially varied among patients who used preopera- 
TABLE 4. Multivariate associations with inpatient narcotic consumption, narcotic dependence at the first postoperative visit, and narcotic dependence at the second postoperative visit*

\begin{tabular}{|c|c|c|c|c|c|c|c|c|c|}
\hline \multirow[b]{2}{*}{ Characteristic } & \multicolumn{3}{|c|}{$\begin{array}{l}\text { Associations w/ Elevated } \\
\text { Inpatient Narcotic } \\
\text { Consumption }\end{array}$} & \multicolumn{3}{|c|}{$\begin{array}{c}\text { Associations w/ Narcotic } \\
\text { Dependence at 1st } \\
\text { Postop Visit }\end{array}$} & \multicolumn{3}{|c|}{$\begin{array}{c}\text { Associations w/ Narcotic } \\
\text { Dependence at 2nd } \\
\text { Postop Visit }\end{array}$} \\
\hline & $\mathrm{RR}$ & $95 \% \mathrm{Cl}$ & $p$ Value & $\mathrm{RR}$ & $95 \% \mathrm{Cl}$ & $p$ Value & $\mathrm{RR}$ & $95 \% \mathrm{Cl}$ & $\mathrm{p}$ Value \\
\hline Age (yrs) & & & 0.104 & & & 0.250 & & & 0.399 \\
\hline $18-39$ & Ref & - & & Ref & - & & Ref & - & \\
\hline $40-49$ & 1.8 & $1.0-3.2$ & & 1.5 & $0.9-2.6$ & & 1.5 & $0.7-3.1$ & \\
\hline $50-59$ & 1.2 & $0.6-2.2$ & & 1.1 & $0.6-2.0$ & & 1.7 & $0.7-3.9$ & \\
\hline$\geq 60$ & 1.6 & $0.8-3.1$ & & 1.8 & $0.9-3.8$ & & 2.6 & $1.0-7.0$ & \\
\hline Sex & & & 0.782 & & & 0.032 & & & 0.332 \\
\hline Female & Ref & - & & Ref & - & & Ref & - & \\
\hline Male & 1.1 & $0.6-1.9$ & & 0.6 & $0.4-1.0$ & & 0.7 & $0.4-1.3$ & \\
\hline Race & & & 0.897 & & & 0.153 & & & 0.172 \\
\hline Other & Ref & - & & Ref & - & & Ref & - & \\
\hline Caucasian & 1.0 & $0.6-1.7$ & & 0.7 & $0.4-1.1$ & & 0.7 & $0.4-1.2$ & \\
\hline Workers' compensation & & & 0.031 & & & 0.004 & & & 0.224 \\
\hline No & Ref & - & & Ref & - & & Ref & - & \\
\hline Yes & 1.8 & $1.1-3.1$ & & 2.1 & $1.3-3.5$ & & 1.5 & $0.8-2.9$ & \\
\hline BMI & & & 0.594 & & & 0.210 & & & 0.337 \\
\hline$\leq 24$ & Ref & - & & Ref & - & & Ref & - & \\
\hline $25-29$ & 0.7 & $0.4-1.3$ & & 1.7 & $0.8-3.4$ & & 2.8 & $0.9-8.4$ & \\
\hline $30-34$ & 1.0 & $0.5-2.0$ & & 1.9 & $0.9-4.1$ & & 2.7 & $0.8-9.7$ & \\
\hline$\geq 35$ & 0.9 & $0.5-1.7$ & & 2.1 & $1.0-4.3$ & & 2.7 & $0.8-9.0$ & \\
\hline Modified CCl & & & 0.511 & & & 0.288 & & & 0.139 \\
\hline 0 & Ref & - & & Ref & - & & Ref & - & \\
\hline 1 & 1.0 & $0.5-1.8$ & & 1.1 & $0.6-2.0$ & & 0.6 & $0.3-1.3$ & \\
\hline 2 & 0.6 & $0.3-1.4$ & & 0.7 & $0.3-1.4$ & & 0.3 & $0.1-1.0$ & \\
\hline VAS score & & & 0.323 & & & 0.808 & & & 0.083 \\
\hline $1-7$ & Ref & - & & Ref & - & & Ref & - & \\
\hline $8-10$ & 1.3 & $0.8-2.0$ & & 1.1 & $0.7-1.6$ & & 1.6 & $0.9-2.8$ & \\
\hline Procedure & & & $<0.001$ & & & $<0.001$ & & & 0.028 \\
\hline ACDF & Ref & - & & Ref & - & & Ref & - & \\
\hline LD & 0.3 & $0.1-0.9$ & & 0.4 & $0.2-0.9$ & & 0.5 & $0.2-1.7$ & \\
\hline TLIF & 2.3 & $1.2-4.2$ & & 1.8 & $1.0-3.0$ & & 1.8 & $0.8-4.3$ & \\
\hline
\end{tabular}

* Values in boldface are statistically significant.

tive narcotics. Second, ILPMP monitoring of prescription medications is limited to 1 year. The actual duration of narcotic utilization may not have been accurately reflected if patients were prescribed medications more than 1 year before the date of surgery. Third, ILPMP documents only prescription medications: the illicit utilization of opioidcontaining medications could not be determined. In addition, ILPMP documents the filling of narcotic medications prior to surgery. The present study used this documentation as a proxy for the preoperative utilization of narcotics. However, it is possible that patients filled prescriptions but did not take the medication. Finally, all patients underwent spine surgery performed by a single surgeon. As a result, the generalizability of the findings to all surgeons in the country may be limited.

\section{Conclusions}

Our findings suggest that determining the actual preoperative narcotic utilization in patients who undergo spine surgery may help optimize postoperative pain management. Approximately $75 \%$ of patients used narcotics preoperatively. Patients who used narcotics preoperatively demonstrated significantly higher inpatient narcotic consumption, but this difference did not persist following discharge. Finally, postoperative narcotic consumption (inpatient and following discharge) was independent of the self-reported accuracy of preoperative narcotic utilization. Taken together, these findings suggest that corroboration between the patient's self-reported preoperative narcotic utilization and other sources of information (e.g., family members and narcotic registries) may be clinically valu- 

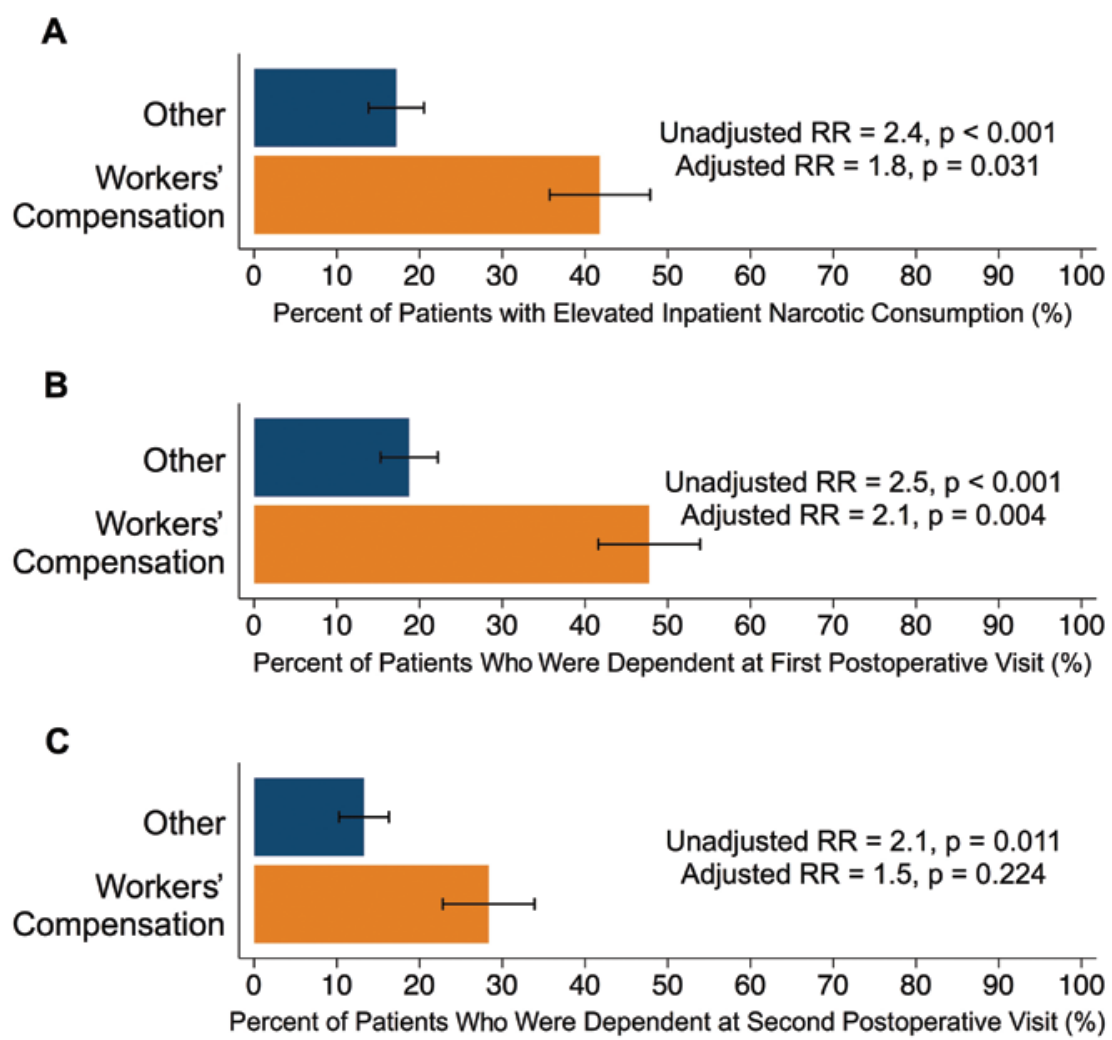

FIG. 2. A: Inpatient narcotic consumption by payer status. B: Narcotic dependence at the first postoperative visit by payer status. C: Narcotic dependence at the second postoperative visit by payer status. The mean values are shown, and the black whiskers indicate standard errors. Figure is available in color online only.
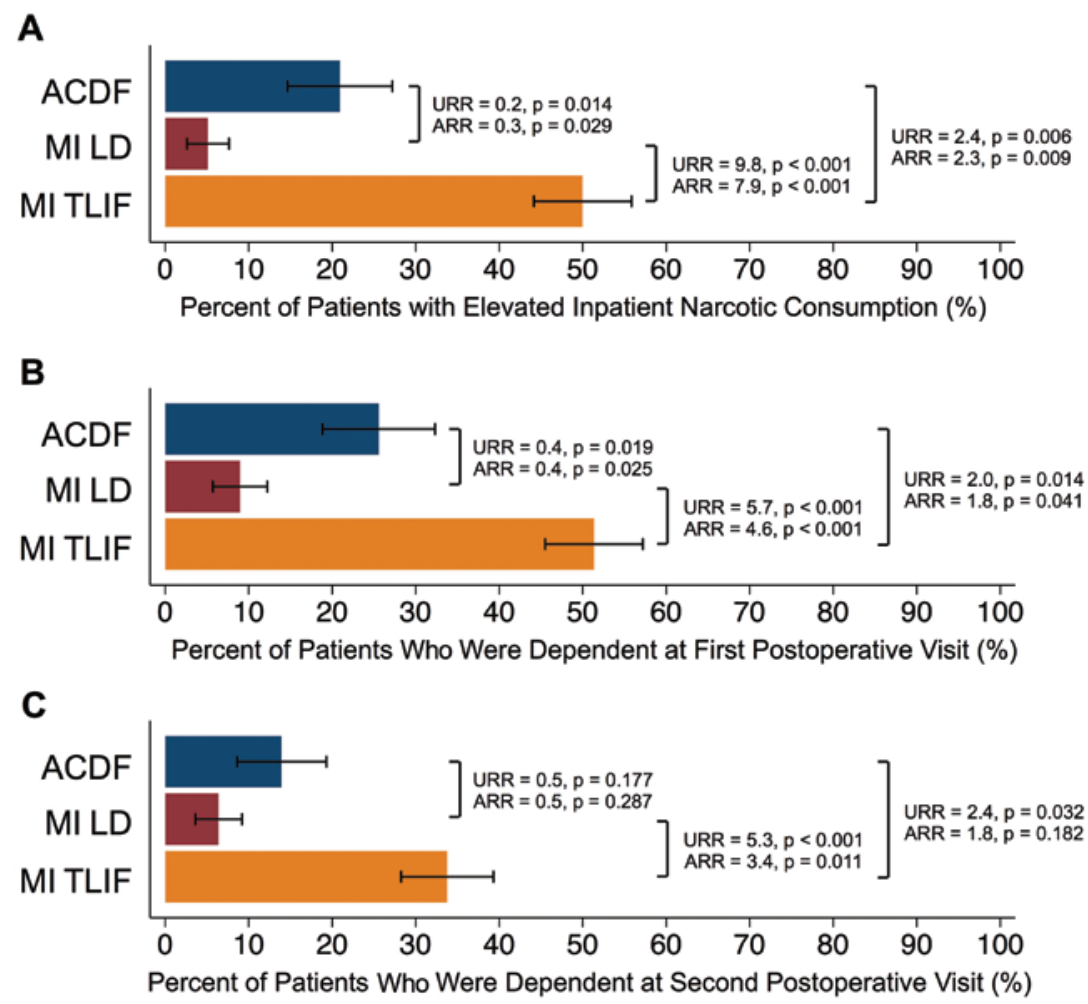

FIG. 3. A: Inpatient narcotic consumption by procedure type. B: Narcotic dependence at the first postoperative visit by procedure type. C: Narcotic dependence at the second postoperative visit by procedure type. The mean values are shown, and the black whiskers indicate standard errors. ARR = adjusted relative risk; LD = lumbar discectomy; $M I$ = minimally invasive; URR = unadjusted relative risk. Figure is available in color online only. 
A

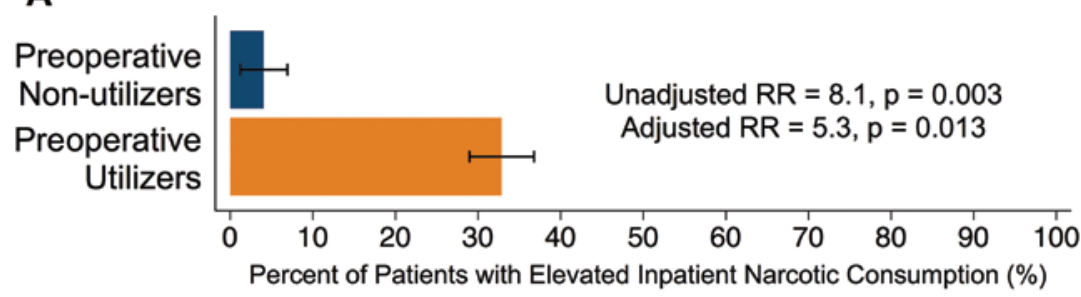

$\mathbf{B}$

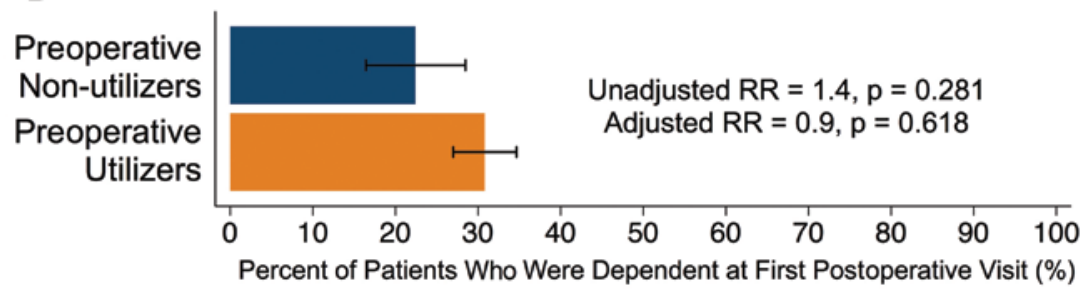

C

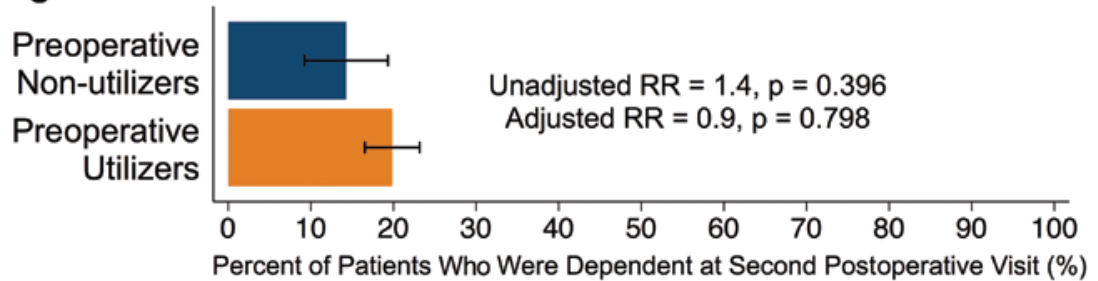

FIG. 4. A: Inpatient narcotic consumption by preoperative narcotic utilization. B: Narcotic dependence at the first postoperative visit by preoperative narcotic utilization. C: Narcotic dependence at the second postoperative visit by preoperative narcotic utilization. The mean values are shown, and the black whiskers indicate standard errors. Figure is available in color online only.

A

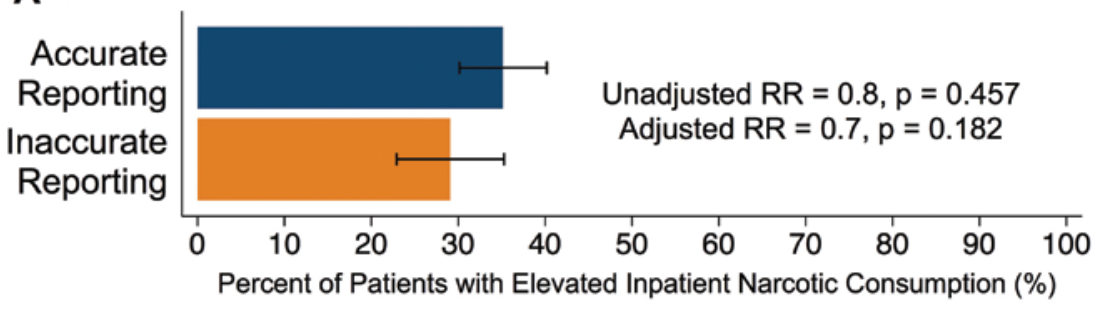

B

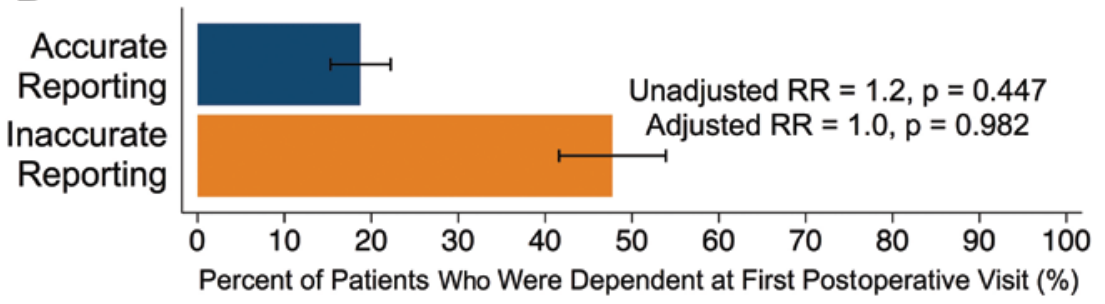

C

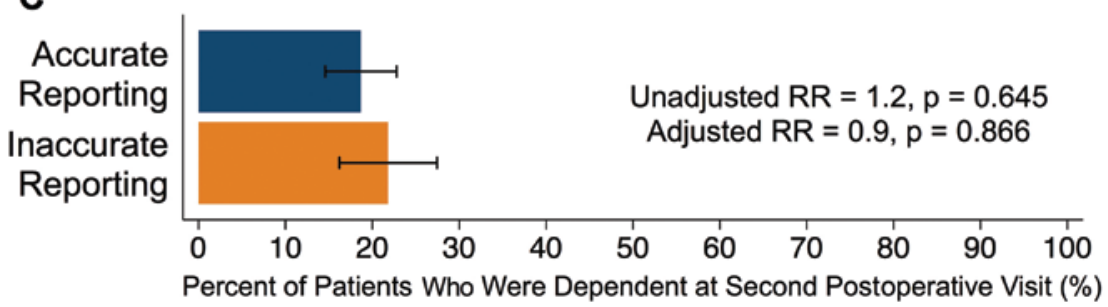

FIG. 5. A: Inpatient narcotic consumption by the accuracy of reporting. B: Narcotic dependence at the first postoperative visit by the accuracy of reporting. C: Narcotic dependence at the second postoperative visit by the accuracy of reporting. The mean values are shown, and the black whiskers indicate the standard errors. Figure is available in color online only. 

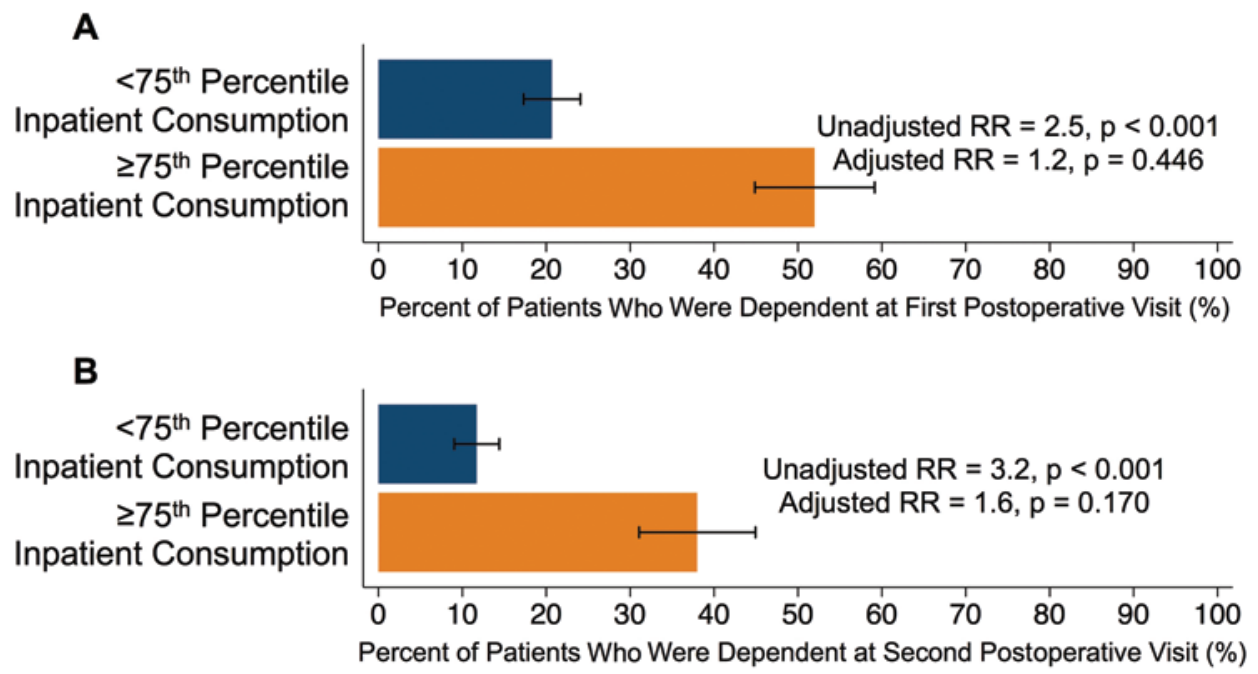

FIG. 6. A: Narcotic dependence at the first postoperative visit by inpatient narcotic consumption. B: Narcotic dependence at the second postoperative visit by inpatient narcotic consumption. The mean values are shown, and the black whiskers indicate the standard errors. Figure is available in color online only.

able with respect to minimizing complications and improving the management of postoperative pain.

\section{References}

1. Armaghani SJ, Lee DS, Bible JE, Archer KR, Shau DN, Kay $\mathrm{H}$, et al: Preoperative narcotic use and its relation to depression and anxiety in patients undergoing spine surgery. Spine (Phila Pa 1976) 38:2196-2200, 2013

2. Carroll IR, Angst MS, Clark JD: Management of perioperative pain in patients chronically consuming opioids. Reg Anesth Pain Med 29:576-591, 2004

3. Caudill-Slosberg MA, Schwartz LM, Woloshin S: Office visits and analgesic prescriptions for musculoskeletal pain in US: 1980 vs. 2000. Pain 109:514-519, 2004

4. Chapman CR, Davis J, Donaldson GW, Naylor J, Winchester D: Postoperative pain trajectories in chronic pain patients undergoing surgery: the effects of chronic opioid pharmacotherapy on acute pain. J Pain 12:1240-1246, 2011

5. Charlson ME, Pompei P, Ales KL, MacKenzie CR: A new method of classifying prognostic comorbidity in longitudinal studies: development and validation. J Chronic Dis 40:373383, 1987

6. Cleves MA, Sanchez N, Draheim M: Evaluation of two competing methods for calculating Charlson's comorbidity index when analyzing short-term mortality using administrative data. J Clin Epidemiol 50:903-908, 1997

7. Deyo RA, Smith DH, Johnson ES, Donovan M, Tillotson CJ, Yang X, et al: Opioids for back pain patients: primary care prescribing patterns and use of services. J Am Board Fam Med 24:717-727, 2011

8. Gordon DB, Stevenson KK, Griffie J, Muchka S, Rapp C, Ford-Roberts K: Opioid equianalgesic calculations. J Palliat Med 2:209-218, 1999

9. Lawrence JT, London N, Bohlman HH, Chin KR: Preoperative narcotic use as a predictor of clinical outcome: results following anterior cervical arthrodesis. Spine (Phila Pa 1976) 33:2074-2078, 2008

10. Mahmud MA, Webster BS, Courtney TK, Matz S, Tacci JA, Christiani DC: Clinical management and the duration of disability for work-related low back pain. J Occup Environ Med 42:1178-1187, 2000

11. Mesfin A, Lenke LG, Bridwell KH, Akhtar U, Jupitz JM, Fogelson JL, et al: Does preoperative narcotic use adversely affect outcomes and complications after spinal deformity surgery? A comparison of nonnarcotic- with narcotic-using groups. Spine J 14:2819-2825, 2014

12. Rapp SE, Ready LB, Nessly ML: Acute pain management in patients with prior opioid consumption: a case-controlled retrospective review. Pain 61:195-201, 1995

13. Webster BS, Verma SK, Gatchel RJ: Relationship between early opioid prescribing for acute occupational low back pain and disability duration, medical costs, subsequent surgery and late opioid use. Spine (Phila Pa 1976) 32:2127-2132, 2007

14. Wheeler M, Oderda GM, Ashburn MA, Lipman AG: Adverse events associated with postoperative opioid analgesia: a systematic review. J Pain 3:159-180, 2002

15. Zywiel MG, Stroh DA, Lee SY, Bonutti PM, Mont MA: Chronic opioid use prior to total knee arthroplasty. J Bone Joint Surg Am 93:1988-1993, 2011

\section{Disclosure}

Dr. Singh is a consultant for Zimmer, Stryker, and Globus and has a financial relationship with Pioneer, Thieme, and Lippincott Williams \& Wilkins.

\section{Author Contributions}

Conception and design: Singh. Acquisition of data: Aboushaala, Elboghdady. Analysis and interpretation of data: Ahn, Bohl, Tabaraee, Aboushaala. Drafting the article: Singh, Ahn, Bohl, Tabaraee, Aboushaala. Critically revising the article: Singh, Ahn, Bohl, Tabaraee, Elboghdady. Reviewed submitted version of manuscript: all authors. Approved the final version of the manuscript on behalf of all authors: Singh. Statistical analysis: Ahn, Bohl. Administrative/technical/material support: Ahn, Bohl, Tabaraee, Aboushaala, Elboghdady. Study supervision: Singh.

\section{Supplemental Information \\ Current Affiliation}

Dr. Bohl: Department of Orthopedic Surgery, Rush University Medical Center, Chicago, IL.

\section{Correspondence}

Kern Singh, Department of Orthopedic Surgery, Rush University Medical Center, 1611 W. Harrison St., Ste. \#300, Chicago, IL 60612. email: kern.singh@rushortho.com. 